Article

\title{
Quantifying the Effect of Crown Vertical Position on Individual Tree Competition: Total Overlap Index and Its Application in Sustainable Forest Management
}

\author{
Boheng Wang ${ }^{1}$, Yuankun Bu ${ }^{1}$, Guanhu Tao ${ }^{1}$, Chenran Yan ${ }^{1}$, Xiaolu Zhou ${ }^{1}$, Weizhong Li ${ }^{1, *}$, \\ Pengxiang Zhao ${ }^{1, *}$, Yanzheng Yang ${ }^{2}$ and Ruikun Gou ${ }^{3}$ \\ 1 College of Forestry, Northwest A\&F University, Yangling 712100, China; vancywang@nwafu.edu.cn (B.W.); \\ 2017050696@nwsuaf.edu.cn (Y.B.); taoguanhu@nwsuaf.edu.cn (G.T.); yanchenran@gmail.com (C.Y.); \\ zhoux1977@163.com (X.Z.) \\ 2 State Key Laboratory of Urban and Regional Ecology, Research Center for Eco-Environmental Science, China \\ Academy of Science, Beijing 100085, China; yanzheng148@163.com \\ 3 Ministry of Education Key Laboratory for Earth System Modeling, Department of Earth System Science, \\ Tsinghua University, Beijing 100084, China; grk@nwsuaf.edu.cn \\ * Correspondence: liweizhong@nwsuaf.edu.cn (W.L.); zhaopengxiang@nwsuaf.edu.cn (P.Z.)
}

Received: 28 July 2020; Accepted: 9 September 2020; Published: 11 September 2020

check for updates

\begin{abstract}
Competition is an essential driving factor that influences forest community sustainability, yet measuring it poses several challenges. To date, the Competition Index (CI) has generally been the tool of choice for quantifying actual competition. In this study, we proposed using the Total Overlap Index (TOI), a CI in which the Area Overlap (AO) index has been adapted and modified to consider the "shading" and "crowding" effects in the vertical dimension. Next, based on six mixed forest plots in Xiaolong Mountain, Gansu, China, we assessed the results to determine the TOI's evaluation capability. Individual-tree simulation results showed that compared to the modified Area Overlap index $\left(\mathrm{AO}_{\mathrm{M}}\right)$, the TOI has superior quantification capability in the vertical direction. The results of the basal area increment (BAI) model showed that the TOI offers the best evaluation capability among the four considered CIs in mixed forest (with Akaike Information Criterion (AIC) of 1041.60 and log-likelihood (LL) of -511.80 in the model fitting test, mean relative error of $-28.67 \%$, mean absolute percent error of $117.11 \%$, and root mean square error of 0.7993 in cross-validation). Finally, the TOI was applied in the Kaplan-Meier survival analysis and Cox proportional-hazards analysis. The Kaplan-Meier survival analysis showed a significant difference between the low- (consisting of trees with the TOI lower than 1) and high-competition (consisting of trees with the TOI higher than 1) groups' survival and hazard curves. Moreover, the results of the Cox proportional-hazards analysis exhibited that the trees in the low-competition group only suffered $34.29 \%$ of the hazard risk that trees in the high-competition group suffered. Overall, the TOI expresses more dimensional information than other CIs and appears to be an effective competition index for evaluating individual tree competition. Thus, the competition status quantified using this method may provide new information to guide policy- and decision-makers in sustainable forest management planning projects.
\end{abstract}

Keywords: competition index; Total Overlap Index; three-dimensional; basal area increment model; tree mortality model; survival and hazard analysis

\section{Introduction}

Sustainable forest management (SFM) is gradually replacing traditional forest management and becoming a new trend for forestry [1]. To ensure the rationality of SFM policy and strategy, decision-makers have to deeply understand processes and impact factors of forest dynamics. As one 
of the elements of forest community sustainability [2], competition highly influences the process of tree mortality, growth, and recruitment [3], which is recognized as one inevitable issue that should be considered in related SFM policy and strategy decision-making [4]. Tree competition is induced by unevenness in trees' spatial distribution, species, and microclimate. Different individuals suffer different pressures in obtaining light, moisture, nutrition, and other resources [5], which may induce the weakness or even the death of some trees. Tree competition of individual trees is a difficult variable to quantify. This is because the environmental conditions and resources of tree growth are ever-changing [5,6]. Researchers have developed various indexes, ranging from size ratio, forest structure, and light transmission [7-9] perspectives to quantifying the competition of individuals and using different parameters; for example: Diameter at Breast Height (DBH) [6,9], tree height $[9,10]$, and relative position of trees [11,12]. Meanwhile, these Competition Indexes (CIs) were based on different neighbor tree selection strategies-e.g., some CIs were based on the angles between trees [13-15], while others were based on a fixed number of trees [11] or a fixed area [9,16].

Based on the evenness of tree competition in the forest, some indexes represent one-sided tree competition-e.g., the Crown Closure at the Top of the Tree (CCH) [17] considers the effect of larger trees. Other indexes represent two-sided competition-e.g., the Crown Competition Factor (CCF) [18], which also considers the impact of all neighboring trees [19]. Moreover, the CIs were classified based on whether the distance between trees was considered [20]. Some researchers have modeled competition among assorted trees by using different variables related to distance, such as relative distance between a subject and its neighbor $[9,11,21,22]$. For example, Hegyi proposed a CI that uses the difference between the DBH and the distance between the subject tree and neighbor trees [9]. However, other researchers focused on developing models to explain the competitive relationship using distance-independent tree parameters or stand-level variables (e.g., mean DBH or mean basal area) [16,23-25]. Of particular note, Hui et al. [11] established a relatively mature spatial structure-based competition index (SCI) that considered several comprehensive factors and summarized the competition pressure from distribution, species composition, size differentiation, and the extent of tree aggregation in a specific stand.

Although the aboveground competition was correlated with mutual inhibition and promotion among different tree species, crown competition is still recognized as the main aboveground competition component [10]. Essentially, the crown undertakes almost all the photosynthetic tasks, which significantly influence the tree's productivity and biomass [26,27]. On the one hand, the crown has been identified as a critical factor influencing the crown's effective photosynthetic area or effective photosynthetic volume [5]. On the other hand, the overlapping relationship among crowns reflects the competitive pressure from space packing and physical crowding, which influences longitudinal and radial tree growth. Thus, the tree crown is considered a reliable factor for assessing the competition among trees. Crown-based CIs have been used in numerous previous studies [15,28,29]. For example, Pretzsch [10] proposed KKL, which represents competition based on the subject tree's opening angles, while Pukkala et al. [16] examined 12 different CIs and their prediction capability. The crown-based CIs were established based on different types of parameters and are generally subdivided into the following four categories: size relationship, size-distance relationship, influence zone relationship, and light competition relationship (based on open-sky view and light interception). In the first group, competition is represented using the crown size ratio. Thus, these CIs are independent of distance. The second group of CIs considers both crown properties and distance, while the third considers the trees' or crowns' potential influence area. The CIs in the fourth group focus on each crown's effective light-interception area or light-interception angle. That being said, using the CIs in the first three groups to evaluate competition in the vertical dimension is extremely challenging in contrast to using the CIs in the fourth group.

The Area Overlap (AO) index [30] has been widely used for predicting forest dynamics, growth, and yield [23,31]. It has also been adapted and modified by numerous researchers [12,32] for various forest types. The AO index is calculated using the area of the influence zone between the subject tree 
and its neighbors in the horizontal dimension. Some researchers promote the idea that tree competition is related to horizontal and vertical dimensions [5,33]. Thus, a proposed modified Area Overlap index $\left(\mathrm{AO}_{\mathrm{M}}\right)$ concerns incorporating the tree height ratio parameter to show the relationship between the subject tree and its neighbors in the vertical dimension. However, the actual competition is related to the vertical position of the crowns, not the tree height, due to the light and the space competition being size-asymmetric in the vertical dimension [34,35]. Furthermore, different combinations of crown positions and crown lengths in the vertical dimension may cause the competition status to vary among the trees, even though they share the same overlapped area in the horizontal dimension. For example (Figure 1), the relative position of crowns in the vertical dimension may generate different types of competition (Figure 1a,b), while the subject tree's crown length (Figure 1a,d) and that of its neighbor (Figure 1a,c) also influence the CIs.
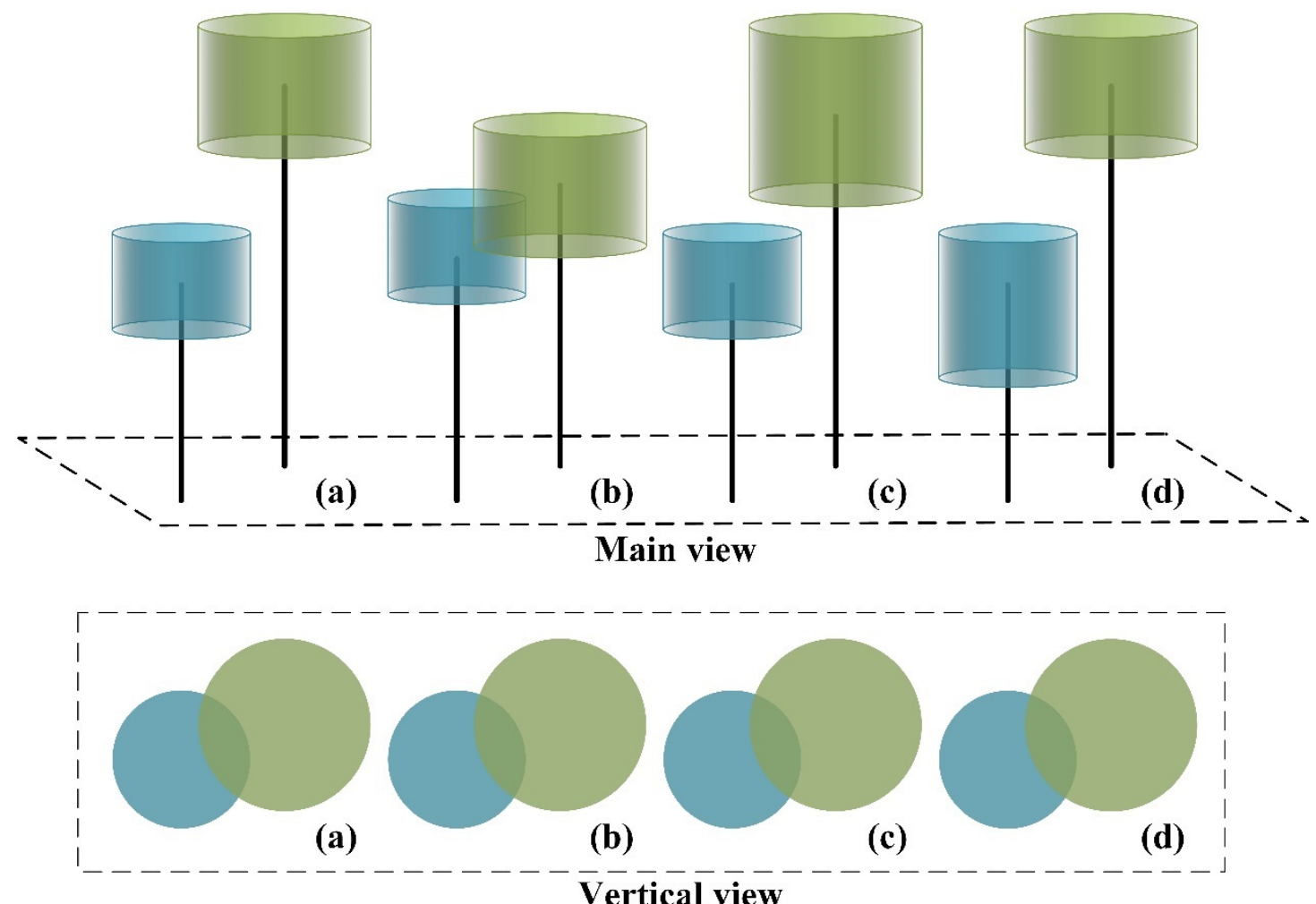

Figure 1. Trees with different vertical competition statuses that exhibit the same crown overlapping area. The green cylinder represents the neighbor tree, while blue represents the subject tree. Main view: (a) the subject tree lower than a neighbor tree whose crown length is relatively small; (b) the subject tree lower than a neighbor tree and share the space with the neighbor tree; (c) the subject tree lower than a neighbor tree whose crown length is relatively big; (d) the subject tree showed a relatively big crown length and lower than a neighbor tree. Vertical view: (a-d) showed same overlapped area between the subject tree and neighbor tree.

Tree mortality is an important process in forest dynamics and a fundamental factor in SFM. It is influenced by the environment, competition tree size, etc., and is modeled by different tree mortality models. The traditional tree mortality model lacks time-dependent data, methodology in hypothesis testing, and censoring of observations [36]. Some scholars proposed using survival analyses in modeling forest mortaility [37]. Survival analysis was developed in medical science and recognized as the basis of new analytical techniques for forest mortality [38]. Time was defined as a critical component of traditional survival analysis. Due to the inherent lack of death times or death ages of individual trees in forest surveys, researchers found that any variables that indicate status changes between the first survey and the re-survey could replace the variable of time or age in 
traditional survival analysis [36]. They succeed in using the growth of diameter at breast height $(\triangle \mathrm{DBH})$ as a hypothetical surrogate for tree age $[36,39,40]$ in refining estimates of tree death.

In this study, we proposed using the Total Overlap Index (TOI), a CI developed by modifying the AO index. To accurately calculate the individual trees' competition in both the horizontal and vertical dimensions, we conceptualized the crown as a three-dimensional entity and evaluated the tree competition based on shading and crowding [41]. Next, we verified the vertical dimension of the TOI's competitive representation and evaluation ability based on six natural forest plots. Finally, we used the TOI and growth in diameter at breast height $(\triangle \mathrm{DBH})$ in applying survival analysis. In summary, the primary objectives of this study were to: (a) propose the use of the TOI, a new CI based on the AO index, to measure tree competition in the horizontal and vertical dimensions; (b) verify the vertical dimension's representational capability and the assessment ability of the new index in simulative and actual competition evaluation; (c) apply the TOI in Kaplan-Meier survival analysis and Cox proportional-hazards analysis, as well as declare the effect of different-level competition on tree mortality trends.

\section{Materials and Methods}

\subsection{Study Area and Data Collection}

The study area (Figure 2) was established in Xiaolong Mountain $\left(104^{\circ} 23^{\prime}-106^{\circ} 43^{\prime} \mathrm{E}, 33^{\circ} 31^{\prime}-34^{\circ} 41^{\prime} \mathrm{N}\right)$, which is part of the western Qinling Mountain range located in Gansu Province, China. The area has an average altitude of $1600 \mathrm{~m}$ and is characterized by a continental monsoon climate. Furthermore, it lies in a transitional region between the temperate and warm temperate zones, with a mean annual temperature of $7-12{ }^{\circ} \mathrm{C}$, mean annual precipitation of $750 \mathrm{~mm}$, and mean annual sunshine duration of $1520-2313 \mathrm{~h}$, as well as an annual average frost-free period of 175 days. The vertical distribution of forest soil showed a significant difference, which showed a mean soil thickness of 30-60 cm and a mean soil $\mathrm{pH}$ of 6.5-7.5. The forest communities mainly consist of Quercus aliena var. acuteserrata, Quercus liaotungensis, Lauraceae. Obtusiloba BI., Pinus armandii Franch. and Tilia tuan Szyszyl. Quercus aliena var. acuteserrata dominates the study area's vegetation and represents $>50 \%$ of the forest composition.

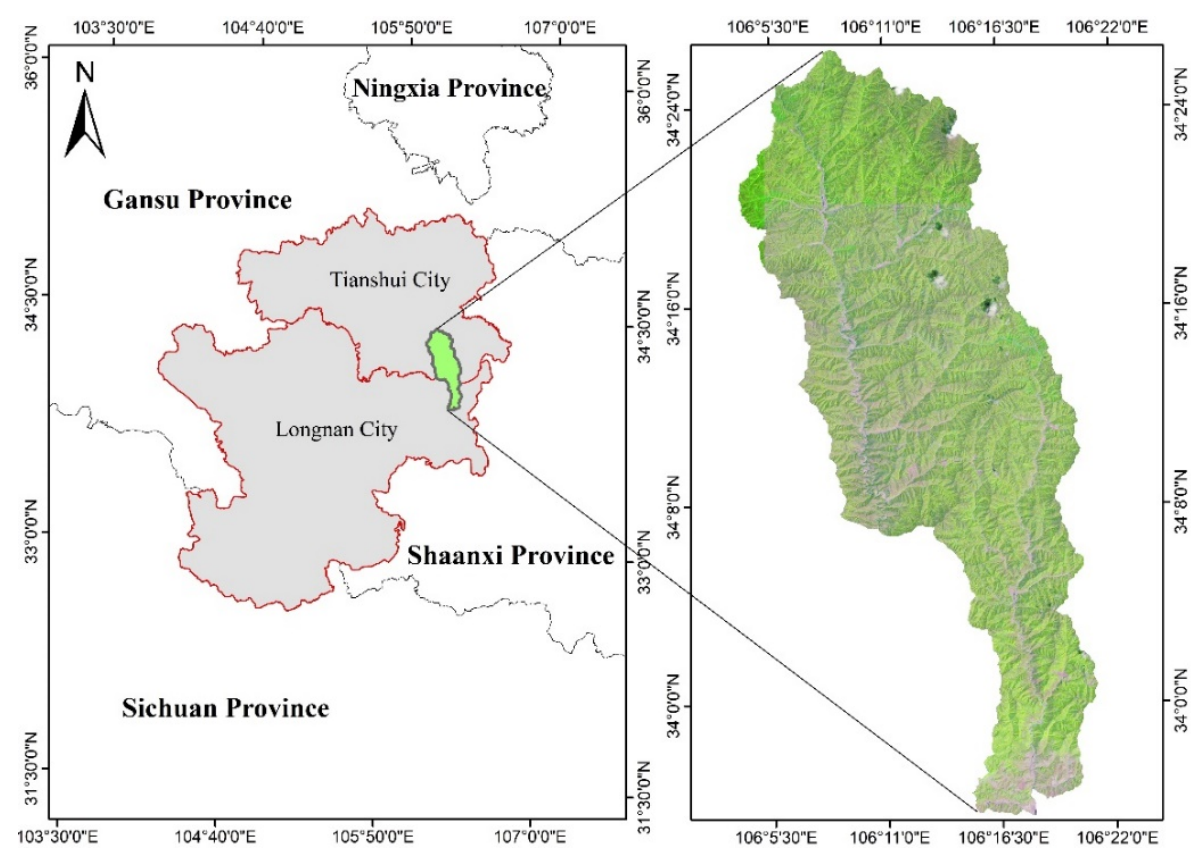

Figure 2. Location of the study sites in Gansu Province, China. 
Compared to the pure forest, the mixed forest showed more complexity in the crowns' vertical structure. Herein, to verify the TOI's vertical evaluation capability, we selected six natural mixed forest plots (Table 1). All six plots were established in May 2008 at an altitude of 1700-1800 m and were resurveyed in 2013. Based on the method proposed by Husch et al. [42], each square plot had a diagonal distance of $40 \mathrm{~m}$ and an overall area of $800 \mathrm{~m}^{2}$. To avoid the edge effect, a $2 \mathrm{~m}$ buffer zone was implemented, which divided the square plot into the buffer area and central plot (Figure 3). In addition, we measured and recorded the DBH (diameter tape, accurate to $0.1 \mathrm{~cm}$ ), tree height (Blume-Leiss height indicator, accurate to $0.5 \mathrm{~m}$ ), clear bole height (sliding staff, accurate to $0.1 \mathrm{~m}$ ), crown diameter (tape measure, accurate to $0.1 \mathrm{~m}$ ), tree age (increment borer), and the relative coordinates of trees in each plot (total station) of all trees with a $\mathrm{DBH} \geq 5 \mathrm{~cm}$. The altitude, aspect, slope, soil layer thickness, and coordinates of each plot were also recorded. The basal area increment (BAI) was calculated based on initial DBH and resurveyed DBH [42].

Table 1. The basic information of the forest plots.

\begin{tabular}{|c|c|c|c|c|c|c|c|c|c|}
\hline \multirow[b]{2}{*}{ NO. } & \multirow{2}{*}{$\begin{array}{l}\text { Slope } \\
\left(^{\circ}\right)\end{array}$} & \multirow{2}{*}{$\begin{array}{l}\text { Altitude } \\
\text { (m) }\end{array}$} & \multirow{2}{*}{$\begin{array}{c}\text { Density } \\
\left.\text { (Tree ha }^{-1}\right)\end{array}$} & \multicolumn{3}{|c|}{ DBH (cm) } & \multirow{2}{*}{$\begin{array}{l}\text { Average } \\
\text { Tree } \\
\text { Height (m) }\end{array}$} & \multicolumn{2}{|c|}{ Coordinates } \\
\hline & & & & Min & $\operatorname{Max}$ & Mean & & $\begin{array}{l}\text { Latitude } \\
\text { (N) }\end{array}$ & $\begin{array}{l}\text { Longitude } \\
\text { (E) }\end{array}$ \\
\hline 1 & 30 & 1757 & 575 & 4.6 & 41 & 16.67 & 16.4 & $34.19279^{\circ}$ & $106.26594^{\circ}$ \\
\hline 2 & 29 & 1745 & 750 & 4 & 50 & 13.67 & 14 & $34.19352^{\circ}$ & $106.26579^{\circ}$ \\
\hline 3 & 35 & 1770 & 1000 & 4.3 & 41.4 & 13.51 & 14.7 & $34.19337^{\circ}$ & $106.26573^{\circ}$ \\
\hline 4 & 31 & 1776 & 1025 & 4.8 & 51 & 13.06 & 14.8 & $34.19396^{\circ}$ & $106.26570^{\circ}$ \\
\hline 5 & 37 & 1712 & 1425 & 4 & 27.8 & 10.91 & 11 & $34.25348^{\circ}$ & $106.23327^{\circ}$ \\
\hline 6 & 37 & 1723 & 2175 & 4.1 & 31.3 & 9.50 & 10.5 & $34.25264^{\circ}$ & $106.23339^{\circ}$ \\
\hline
\end{tabular}

The mean dominant height was used to indicate the average tree height in each plot.

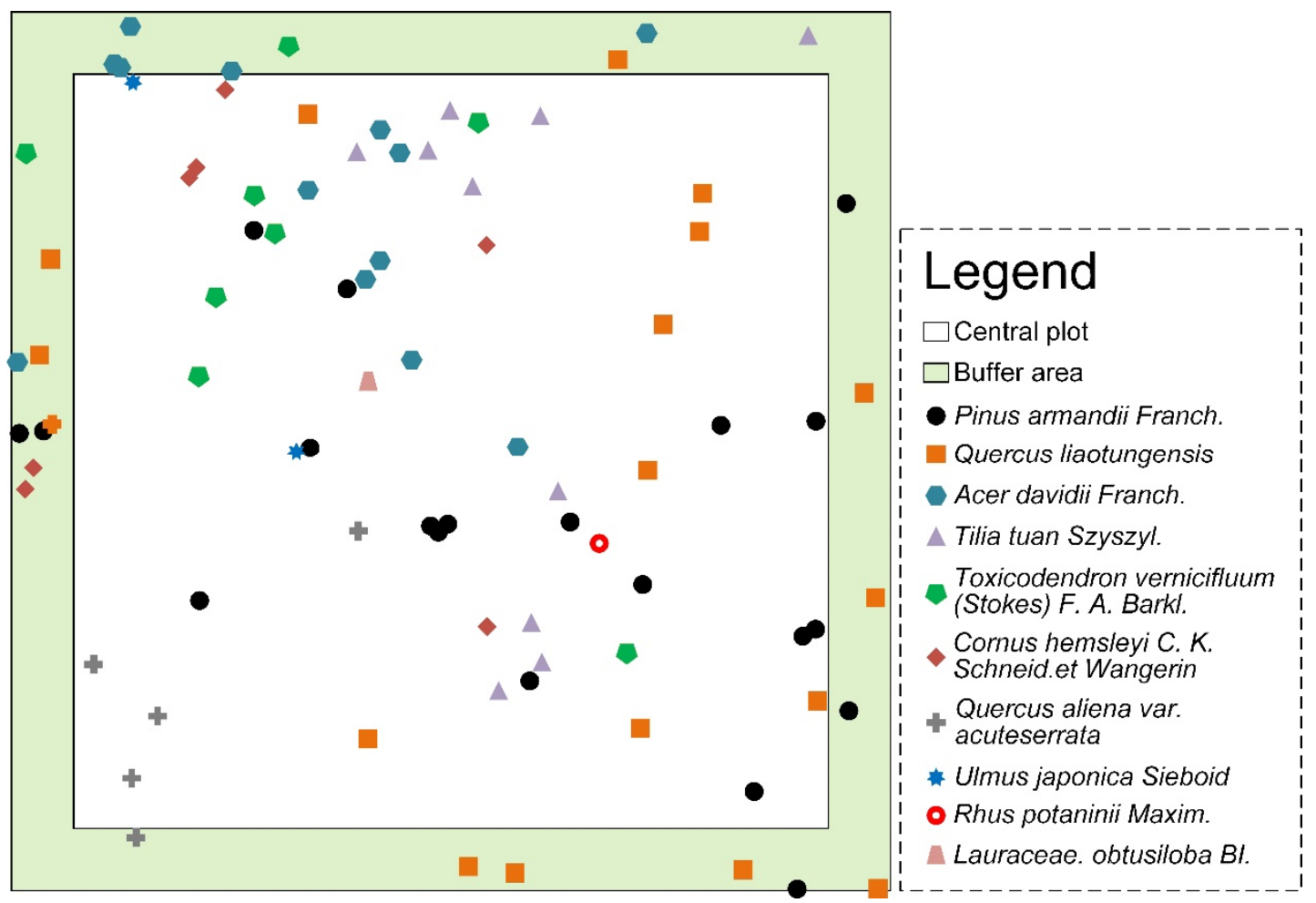

Figure 3. The distribution of trees species in Plot 1. 


\subsection{Selection of the Subject Trees and Neighbor Trees}

To calculate the CIs of each individual tree within each plot, all trees in the central plot (as declared in Section 2.1 and shown in Figure 3) were recognized as subject trees. Based on the method proposed by Bella [23] and Opie [30], we defined the neighbor trees as those whose crown projection connected to the subject tree's crown projection. The canopy projection relationship between trees was assessed using their relative coordinates and crown diameter, as follows:

$$
\text { canopy project relationship }=\left\{\begin{array}{rl}
\text { Shared no projection area, } & R+r \leq l \\
\text { Shared projection area, } & l<R+r
\end{array},\right.
$$

\subsection{TOI Model Algorithm}

The Area Overlap index (AO) is calculated using a horizontal area ratio of the influence zone of trees and represents the resource competition among trees in the horizontal direction [12,23]. The equation of the $\mathrm{AO}$ index was defined as:

$$
A O_{i}=\sum \frac{a_{i j}}{C A_{i}},
$$

where $a_{i j}$ is the overlapped area between crowns of subject tree $i$ and its neighbor tree $j, C A_{i}$ is the crown area of subject tree $i$, and $A O_{i}$ is the Area Overlap index of tree $i$. However, the competitive pressure on trees is also present in the vertical dimension. Due to individual differences in crown length and vertical position, subject trees compete for vertical dimensional light and space in different competition levels. Thus, as proposed by Canham et al. [43], we divided the competitive states of individual trees based on the concepts of "shading" and "crowding", and modified the AO index using two crown-relationship-based parameters: shading and crowding modification coefficients. The shading modification coefficient was defined as a representation of the effective photosynthetic thickness and shaded thickness of a crown, while the crowding modification coefficient was defined as a representation of space packing and physical crowding. We defined the TOI's formula as follows:

$$
\left\{\begin{array}{c}
\text { TOI }_{i}=\sum \text { shading }_{i j}+\sum \text { crowding }_{i j} \\
\text { shading }_{i j}=\frac{a_{i j}}{C A_{i}} \times \theta \\
\text { crowding }_{i j}=\frac{a_{i j}}{C A_{i}} \times \varphi
\end{array},\right.
$$

where $a_{i j}$ is the overlapped area between the crowns of subject tree $i$ and its neighbor tree $j ; C A_{i}$ is the crown area of subject tree $i ; \theta$ is the modification coefficient of shading; $\varphi$ is the modification coefficient of crowding; shading $g_{i j}$ and crowding $_{i j}$ indicate the shading and crowding models that subject tree $i$ suffers from neighbor tree $j$, respectively. Both shading $i_{i j}$ and crowding $_{i j}$ are the volume ratios in three-dimensional space rather than area ratios in the AO index. Because separating the light radiation transfer is hard [44] and generating a three-dimensional model is challenging, the shading and crowding models are based on two hypotheses: (a) The crown shapes of all the trees were recognized as symmetrical cylinders [45], and (b) the cylinders were considered homogeneous, suggesting that light radiation losses were the same when light passed through crowns of the same thickness.

\subsubsection{Shading Modification Cofficient}

Light interception can be an effective competition predictor [46]. Neighbor and subject crowns' projected areas, effective photosynthetic thickness, and shaded thickness control the total amount of light radiation that passes through the subject crown. Thus, we improved the $\mathrm{AO}$ index by adding the vertical dimensional shading status of subject trees. Moreover, we divided the "shading" competition status into three different groups (Figure 4): competition status (a)—the neighbor tree's clear bole height is not lower than the subject tree's height; competition status (b)-the neighbor tree's height is 
higher, while its clear bole height is lower than the subject tree's height; and competition status (c) - the tree height of the subject tree is not lower than the tree height of its neighbor. A shading coefficient $(\theta)$, which demonstrates how these three groups of competition statuses were used to modify the AO index, is expressed as follows:

$$
\theta=\left\{\begin{array}{l}
\frac{h_{1}}{h_{2}}, \text { competition status }(a) \\
\frac{h_{3}}{h_{4}}, \text { competition status }(b) \\
0, \text { competition status }(c)
\end{array}\right.
$$

where $h_{1}$ and $h_{3}$ are the neighbor trees' crown lengths under different competition statuses, and $h_{2}$ and $h_{4}$ are the lengths from the subject tree's treetop to the neighbor tree's treetop in different competition statuses. $\theta$ is a modification coefficient and was calculated based on parameters that could influence the amount of light radiation. For example, in competition status (a), the calculation of $\theta$ considered the crown thickness and the thickness of gaps between crowns. In competition status (b), only the neighbor crown's effective thickness was considered. In competition status (c), the subject tree suffered no shading competition pressure from the neighbor tree.

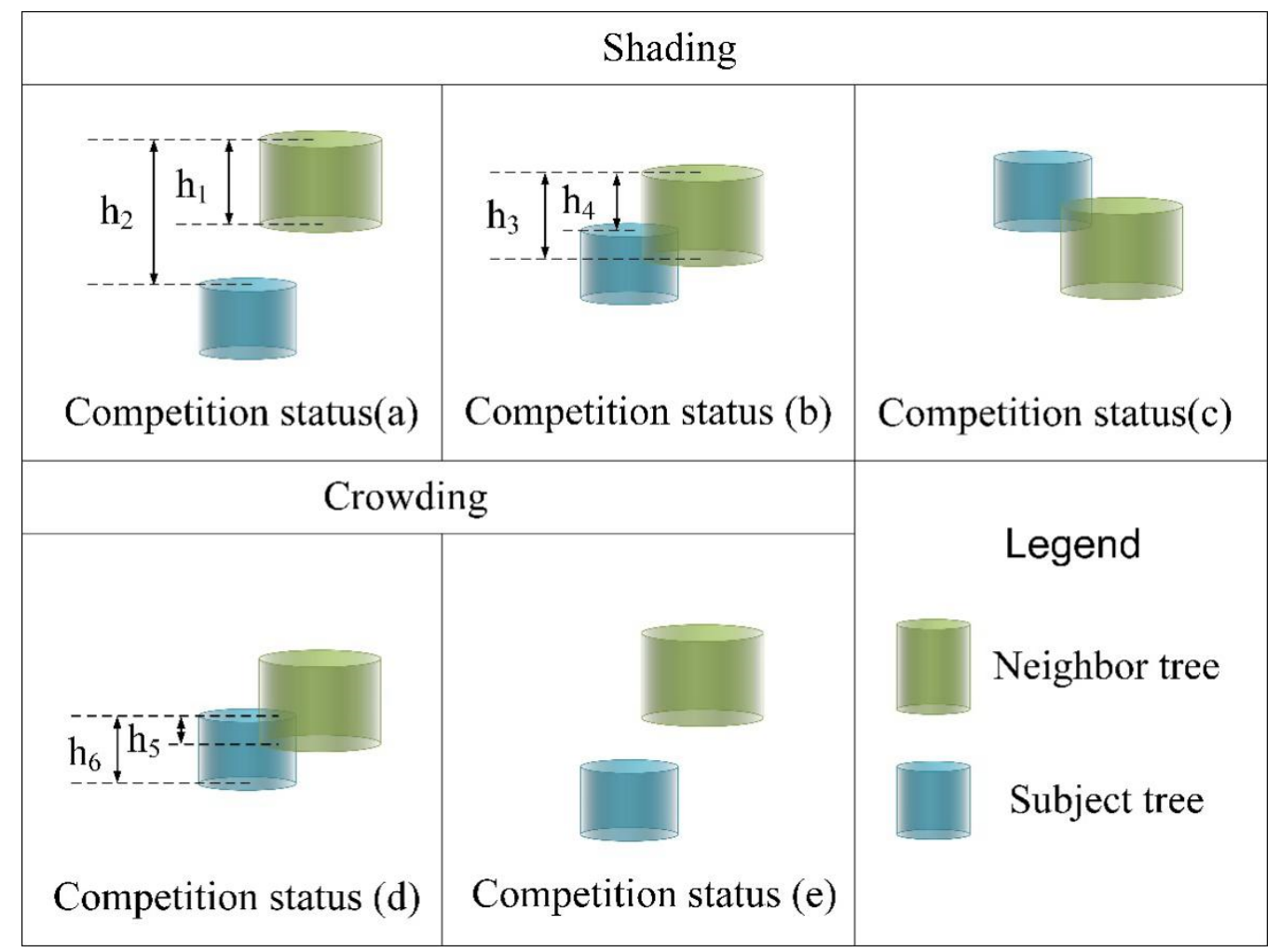

Figure 4. Shading and crowding relationship between the subject and neighbor trees. The blue and green cylinders represent the crowns of the subject and neighbor trees, respectively. The competition status $(\mathbf{a}-\mathbf{c})$ diagrams indicate the shading effect, and $(\mathbf{d}, \mathbf{e})$ indicate the crowding effect that the subject tree suffers from the neighbor tree.

\subsubsection{Crowding Modification Cofficient}

The subject tree's growth is also highly influenced by competitive pressure from space packing and physical crowding [41]. These competitive pressures originate from branch interlacing, and may reduce the subject tree's vigor by facilitating foliage and branch loss. To precisely describe these competitive pressures, we used a three-dimensional cylinder based on crown abstraction in the "crowding" model, as opposed to using projected circles in the AO index. Using the crown length and vertical position 
of each tree, we modified the AO index by adding the trees' vertical crowding status and dividing the "crowding" competition status into two distinct groups (Figure 4): competition status (d)—where the subject tree's crown shared space with its neighbor in the vertical dimension; and competition status (e)—where the subject tree's crown shared no space with its neighbor in the vertical dimension. To quantitatively describe these different crowding statuses, we proposed a crowding coefficient $(\varphi)$, as follows:

$$
\varphi=\left\{\begin{array}{c}
\frac{h_{5}}{h_{6}}, \text { competition status }(d) \\
0, \text { competition status }(e)
\end{array},\right.
$$

where $h_{5}$ is the length of the area where the crowns overlap, and $h_{6}$ is the crown length of the subject tree. We defined $\varphi$ as another modification coefficient that indicates the proportion of shared volume.

\subsection{Individual-Tree Simulation}

Trees suffer competition pressure in the vertical direction. Although the subject tree and its neighbor share the same horizontal overlapping area, the subject tree's competition status may change in response to the crown relationship being altered in the vertical direction. To test the possibility of the TOI expressing changes in the vertical competition status, we proposed individual-tree simulations. In these simulations, a subject tree and a neighbor tree were generated based on vertical crown relationships. The subject tree exhibited a random tree height (from 5.1 to $20 \mathrm{~m}$ ), as well as a random clear bole height (from 5 to $19.9 \mathrm{~m}$ ). The neighbor tree had a fixed tree height and clear bole height of $15 \mathrm{~m}$ and $10 \mathrm{~m}$, respectively. In addition, we assumed that the horizontal overlapping area between the subject tree and its neighbor was constant to ensure the same horizontal competition status. To show the different effects of the vertical dimension's algorithm on the competition index, we calculated the TOI and a modified area overlap index $\left(\mathrm{AO}_{\mathrm{M}}\right)$, proposed by Ek and Monserud [24], for the subject tree in each simulation. The formula of $\mathrm{AO}_{\mathrm{M}}$ was defined as:

$$
A O_{M i}=\sum\left(A O_{i j} \times \frac{H_{j}}{H_{i}}\right)
$$

where $A O_{i j}$ is the area overlap index of subject tree i from neighbor tree $j ; H_{i}$ and $H_{j}$ are the tree height of subject tree $i$ and neighbor tree $j$, respectively; and $A O_{M i}$ is the modified area overlap index of subject tree $i$.

\subsection{Growth Model}

Compared with other competition indexes, the TOI can express both the horizontal and the vertical competition status of the trees. To verify the plausibility of adding vertical competition status in CIs to evaluate the actual competition of the trees, we compared the TOI, $\mathrm{AO}_{\mathrm{M}}$ index, Simple Competition index (Hegyi index) [9], and SCI [11] based on growth models. The formulas of the Hegyi index [9] and SCI [11] are defined as:

$$
\begin{aligned}
& \text { Hegyi index } x_{i}=\sum\left(\frac{d b h_{j}}{d b h_{i}} \times l_{i j}\right), \\
& S C I=\sqrt{U_{i} \times C_{i} \times \lambda_{W_{i}} \times \lambda_{M_{i}}},
\end{aligned}
$$

where $d b h_{i}$ and $d b h_{j}$ are the diameters at breast height (DBH) of subject tree $i$ and neighbor tree $j$, respectively; $U_{i}$ and $C_{i}$ are the dominance and crowding indexes of subject tree $i$, respectively; $\lambda_{W_{i}}$ and $\lambda_{M_{i}}$ are the weighting factors for the neighbor tree's spatial distribution and species identity, respectively.

The basal area increment (BAI) model is a widely used tree growth model, which is highly influenced by competition among trees. The BAI model's model-fitting goodness can be improved by incorporating CIs [47]. Thus, we verified the CIs' evaluation capability by comparing the BAI models after incorporating the $\mathrm{AO}_{\mathrm{M}}$, Hegyi index, $\mathrm{SCI}$, and TOI. The BAI models were then applied in our 
plots. Based on the Wykoff model [48], the BAI was represented as a function of the independent variables of tree size, site condition, and competition. It is mathematically expressed as follows:

$$
\ln \mathrm{BAI}=f(\text { Treesize })+f(\text { Site })+f(\text { Competition }),
$$

The tree size data used in modeling were collected and re-collected at different periods and were recognized as mutually dependent observations that showed a strong autocorrelation. Thus, the mixed linear model was selected for our study to avoid the error caused by data aggregation. Herein, based on the correlation relationship and the biological process associated with tree growth, three fixed variables were selected to represent tree size, including DBH, tree height, and crown-diameter-DBH ratio. In addition, the soil thickness ratio was selected as a representation of the site condition of each plot. The structure-based competition index (SCI) was selected as the benchmark CI in the BAI models to estimate the goodness of different CIs. Furthermore, the tree species was treated as the random variable in the model. The initial BAI model was presented as:

$$
\ln \mathrm{BAI}_{i}=b_{0}+\left(b_{1} \cdot \mathrm{DBH}_{i}\right)+\left(b_{2} \cdot \mathrm{H}_{i}\right)+\left(b_{3} \cdot \mathrm{DC}_{i}\right)+\left(b_{4} \cdot \frac{S T_{O A}}{S T_{O B}}\right)+b_{5} \cdot \mathrm{SCI}+\mu_{s p}+\varepsilon_{i}
$$

where $i$ represents tree $i$ in BAI model; BAI is the five-year basal area increment; DHB is the initial diameter at breast height; $\mathrm{H}$ is the tree height; $\mathrm{DC}$ is the crown-diameter-DBH ratio; $S T_{O A}$ is the total thickness from the soil's O-layer to the A-layer; $S T_{O B}$ is the total thickness from the soil's O-layer to the B-layer; $\mathrm{SCI}$ is the structure-based competition index; $\varepsilon$ is the random error; $\mu_{s p}$ is the random variable of tree species; and $b_{0} \sim b_{5}$ are the parameters to be estimated. The within-subject covariance structure effectively eliminated the autocorrelation of mutually dependent observations and improved the accuracy of mixed models [49]. In our study, we compared the initial BAI model, which incorporated no covariance structure, and the initial model, which incorporated the autoregressive covariance structure $(\mathrm{AR}(1))$ based on the fitting goodness parameters-including the Akaike Information Criterion (AIC), Likelihood Ratio Test (LRT), and log-likelihood (LL). The model with better fit goodness was selected as the benchmark BAI model.

The comparison among the CIs was based on the benchmark BAI models. By replacing the benchmark CI, a group of BAI models incorporating the abovementioned CIs was established. These models were validated via 600 replications using the 0.632 bootstrap method. This technique, which was proposed by Efron [50], has been recognized as a very effective mixed model cross-validation method [51] and uses a validation dataset that was established based on data resampling. In contrast to the conventional bootstrap method, the 0.632 bootstrap method prediction errors were calculated by a subset of original data not included in the bootstrap sample to eliminate its downward bias [51]. The evaluation was based on mean relative error (MRE), mean absolute percent error (MAPE), and root mean square error (RMSE). The MRE, MAPE and RMSE were calculated as follows:

$$
\begin{gathered}
\text { MRE }=\frac{\sum_{i=1}^{n} \frac{y_{i}-\widehat{y_{i}}}{y_{i}}}{n} \times 100 \%, \\
\text { MAPE }=\frac{\sum_{i=1}^{n}\left|y_{i}-\widehat{y_{i}}\right| / y_{i}}{n} \times 100 \%, \\
\text { RMSE }=\sqrt{\frac{\sum_{i=1}^{n}\left(y_{i}-\widehat{y_{i}}\right)^{2}}{n}},
\end{gathered}
$$

where $y_{i}$ is the observed BAI, $\widehat{y_{i}}$ is the predicted BAI, and $n$ is the number of observations in the bootstrapping validation dataset. 


\subsection{Survival and Hazard Analysis}

In our study, we applied the TOI in survival analysis to declare the effects of different levels of competition on tree mortality trends. We firstly divided dead trees in our plots into two different groups. The threshold value used in grouping was calculated based on the TOI value of all trees by K-means clustering. Then, a Kaplan-Meier analysis was performed to explore if mortality curves are significantly different between the two groups. The Kaplan-Meier functions were used to calculate the probability distribution of mortality, which comprises a survival function (Equation (14)) and hazard function (Equation (15)), and is expressed as [36,52]:

$$
\begin{gathered}
S(t)=P(T>t), \\
h(t)=\lim _{\Delta t \rightarrow 0} \frac{P(t \leq T \leq t+\Delta t \mid T \geq t)}{\Delta t},
\end{gathered}
$$

where $S(t)$ is the probability that death occurs at time T. The time T is at least as great as time $t . h(t)$ is the probability that death occurrs exactly at time t. Finally, a Cox proportional-hazards analysis was performed between two competition groups, which showed the different effects of competition status on tree mortality. The Cox function (Equation (16)) is expressed by the hazard function and can be written as a linear regression:

$$
\mathrm{h}(\mathrm{t})=\mathrm{h}_{0}(\mathrm{t}) \times e^{\mathrm{bx}},
$$

where $h(t)$ is the hazard function, $h_{0}(t)$ is the baseline hazard, which is equal to the value of the hazard when covariate $x$ is equal to zero, and $b$ is the coefficient of the covariate variable. The time in our research was replaced by $\triangle \mathrm{DBH}$.

\subsection{Statistical Analysis}

The establishment of the TOI, the individual-tree simulation, Spearman correlation analysis, the regression of the growth model, and the stand simulation were all performed in R software (ver-3.6.1) using the basic module. The model fitting and cross-validation in the BAI model were calculated using the "nlme" and "sjstats" packages in R software, while the Kaplan-Meier survival analysis and Cox proportional-hazards analysis were based on the "survival" and "survminer" packages. Th relevant figures in this study were created in the "corrplot" package, "ggplot2" package, and "vioplot" packages in R software, ArcGIS/ArcGIS version 10.2 (ESRI, Redlands, CA, USA) and Origin/OriginPro 2018C (OriginLab Corporation, Northampton, MA, USA).

\section{Results}

\subsection{Vertical Dimension Representational Ability}

In the individual-tree simulation, we tested the efficacy of the $\mathrm{AO}_{\mathrm{M}}$ index and TOI to express vertical competition. In general, the TOI and $\mathrm{AO}_{\mathrm{M}}$ index value distribution exhibited significant discrepancies throughout the simulations (Figure 5). The $\mathrm{AO}_{\mathrm{M}}$ index showed a negative correlation with the subject tree's height and was not influenced by the clear bole height (Figure 5a). The maximum and minimum of the $\mathrm{AO}_{\mathrm{M}}$ index values appeared when the tree height of the subject tree was 5 and $20 \mathrm{~m}$, respectively. Overall, the $\mathrm{AO}_{\mathrm{M}}$ value distribution was unable to express vertical changes in the relationship between crowns. The subject tree's TOI value is highly influenced by both tree height and clear bole height (Figure 5b). The minimum TOI value appeared when the subject tree's clear bole height and tree height were $(15,20]$. Under this condition, the lowest part of the subject crown is higher than the highest part of its neighbor's crown; thus, the subject tree did not suffer competitive pressure from the neighbor's crown. The maximum part of the TOI value appeared when the subject tree's height was [10,15], and the clear bole height was around $10 \mathrm{~m}$. Under this condition, the subject tree suffered both relatively high "shading" and "crowding" pressure from the neighbor tree. Overall, 
the TOI values' distribution trend indicates that the TOI can express changes in the relationship between crowns.

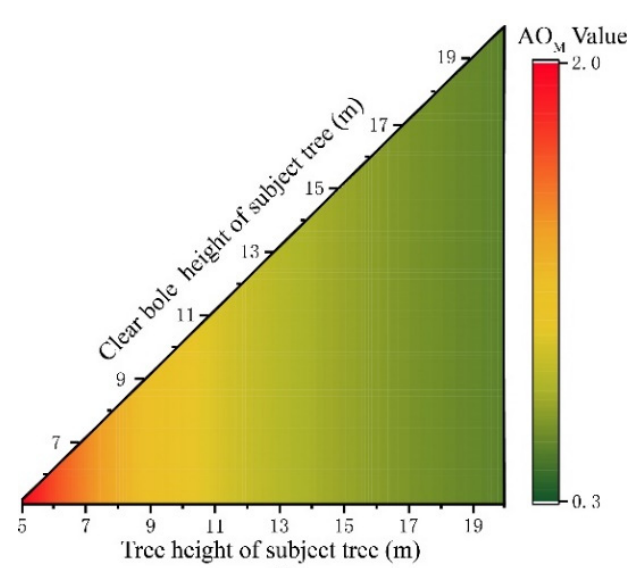

(a)

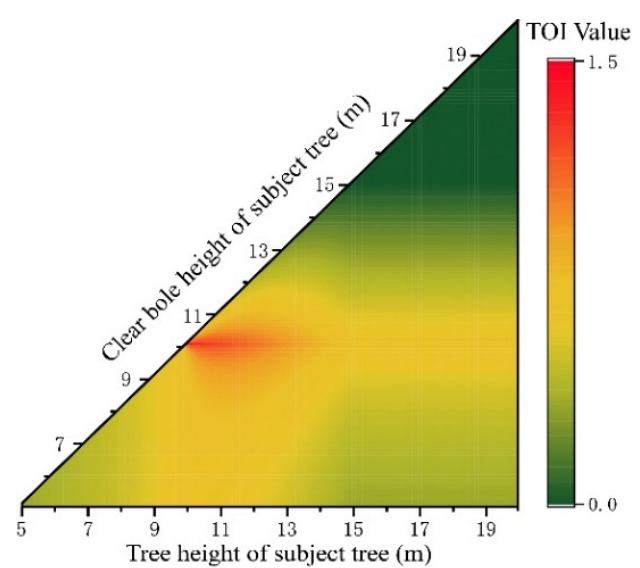

(b)

Figure 5. The Competition Index (CI) values of a subject tree in individual-tree simulations: (a) $\mathrm{AO}_{\mathrm{M}}$, modified Area Overlap index; (b) TOI, Total Overlap Index.

\subsection{Growth Model}

In selecting the benchmark BAI model's covariance structure, we tested model fitting parameters of the initial BAI models with no covariance structure and with the AR(1) covariance structure, respectively (Table 2). The initial model with the AR(1) covariance structure showed an AIC value of 1042.83 and an LL value of -512.42 . These results indicate that this model performed better than the initial model with no covariance structure, which depicted an AIC value of 1050.27 and an LL value of -517.13. Furthermore, the likelihood ratio test between initial models with the AR(1) covariance structure and no covariance structure exhibited an LRT value of $9.437(p<0.01)$, which indicates a significant improvement after the AR(1) covariance structure was incorporated into the initial model. We also compared models that incorporated the $\mathrm{AO}_{\mathrm{M}}$, TOI, SCI, and Hegyi index based on the benchmark BAI model, respectively. Table 3 shows the model fitting and the model validation statistics for the benchmark BAI model and models that incorporated the other three CIs. According to model fitting statistics, the model incorporating the TOI showed the best performance, with an AIC value of 1041.60 and an LL value of -511.80 . The models incorporating the $\mathrm{AO}_{\mathrm{M}}$ index and the benchmark BAI model followed, with similar AIC and LL values of 1042.44, -512.22 and 1042.83, -512.42 , respectively. The model incorporating the Hegyi index performed the poorest, with the highest AIC (1054.96) and the lowest LL (-518.48) value. With respect to model validation statistics, the MRE, MAPE, and RMSE showed that the model incorporating the $\mathrm{TOI}$ and $\mathrm{AO}_{\mathrm{M}}$ index performed better than the benchmark BAI model, while the model incorporating the Hegyi index performed more poorly than the benchmark BAI model. The best MRE (-28.67\%), MAPE (117.11\%), and RMSE (0.7993) are from the model incorporating the TOI. Based on both model fitting and validation performance, independent incorporation of the four CIs produced model trends: $\mathrm{TOI}>\mathrm{AO}_{\mathrm{M}}>\mathrm{SCI}>$ Hegyi index. These results indicate that the TOI offers the best evaluation capability among the four CIs in mixed forests. 
Table 2. The model parameter estimates and model fitting goodness of the initial basal area increment (BAI) model with different covariance structures.

\begin{tabular}{|c|c|c|c|c|c|c|c|c|c|c|}
\hline \multirow{2}{*}{ Model } & \multicolumn{6}{|c|}{ Parameter Estimates } & \multicolumn{4}{|c|}{ Model Fitting } \\
\hline & $\mathbf{b}_{0}$ & $b_{1}$ & $b_{2}$ & $b_{3}$ & $\mathbf{b}_{4}$ & $\mathbf{b}_{5}$ & AIC & LL & LRT & $p$-Value \\
\hline Initial model & $4.675^{* * *}$ & $5.535 * * *$ & $4.265^{* * *}$ & $-2.872 * *$ & $2.481 *$ & $-3.859^{* * *}$ & 1050.27 & -517.13 & & \\
\hline $\begin{array}{l}\text { Initial model } \\
\text { with AR(1) }\end{array}$ & $3.770 * * *$ & $5.464^{* * *}$ & $4.459^{* * *}$ & $-2.214^{*}$ & $2.368^{*}$ & $-3.661^{* * *}$ & 1042.83 & -512.42 & 9.437 & 0.0021 ** \\
\hline
\end{tabular}

Table 3. Model fitting goodness and cross-validation statistics of BAI models incorporating four CIs.

\begin{tabular}{cccccc}
\hline \multirow{2}{*}{ Selected CI } & \multicolumn{2}{c}{ Model Fitting } & \multicolumn{3}{c}{ Cross-Validation } \\
\cline { 2 - 6 } & AIC & LL & MRE & MAPE & RMSE \\
\hline Benchmark CI (SCI) & 1042.83 & -512.42 & $-35.46 \%$ & $122.05 \%$ & 0.8053 \\
TOI & 1041.60 & -511.80 & $-28.67 \%$ & $117.11 \%$ & 0.7993 \\
AOM & 1042.44 & -512.22 & $-28.88 \%$ & $118.87 \%$ & 0.8049 \\
Hegyi index & 1054.96 & -518.48 & $-37.53 \%$ & $127.81 \%$ & 0.8174
\end{tabular}

TOI, Total Overlap Index; $\mathrm{AO}_{\mathrm{M}}$, modified Area Overlap Index; Hegyi index, Simple competition index; AIC, Akaike Information Criterion; LL, Log-Likelihood; MRE, mean relative error; MAPE, mean absolute percent error; RMSE, root mean square error.

\subsection{Kaplan-Meier Survival Analysis and Cox Proportional-Hazards Analysis}

Based on the K-means cluster results of the TOI values, we divided the dead trees into two groups. The dead trees whose TOI values were lower than 1 belonged to the low-competition group; otherwise, they belonged to the high-competition group. The results of the Kaplan-Meier analysis (Figure 6a) showed that the survival probability of the low-competition group is higher than that of the high-competition group, which indicated that higher competition might induce the increase of trees' death rate. The $50 \%$ survival probability showed when $\triangle \mathrm{DBH}$ reached 0.4 in the high-competition group and 1.1 in the low-competition group (Figure 6a). For both the low- and high-competition groups, the curve of cumulative hazard increases while $\triangle \mathrm{DBH}$ increases (Figure $6 \mathrm{~b}$ ), which indicated that trees with a faster growth rate faced a higher hazard of death. The coefficient of the Cox analysis (Table 4) was -1.0703 and passed three different tests, indicating that trees in the high-competition group suffer a higher risk of death than trees in the low-competition group. The hazard ratio in the Cox analysis was 0.3429 , which indicated that trees in the low-competition group had a reduction of $65.71 \%$ (or suffered only $34.29 \%$ ) of hazard risk compared to the high-competition group.

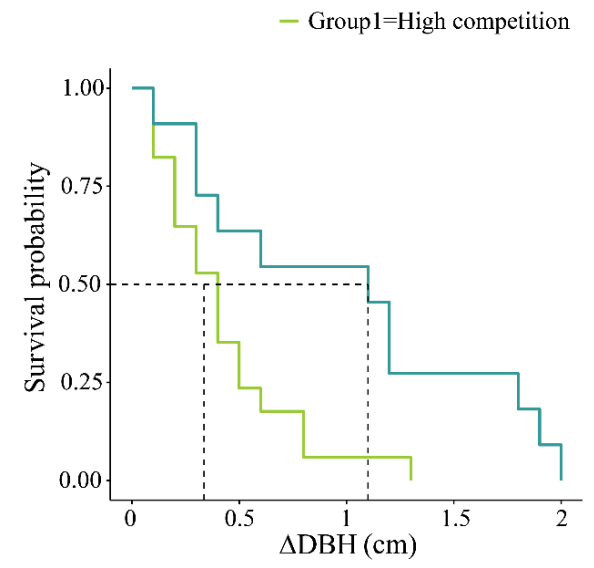

(a)

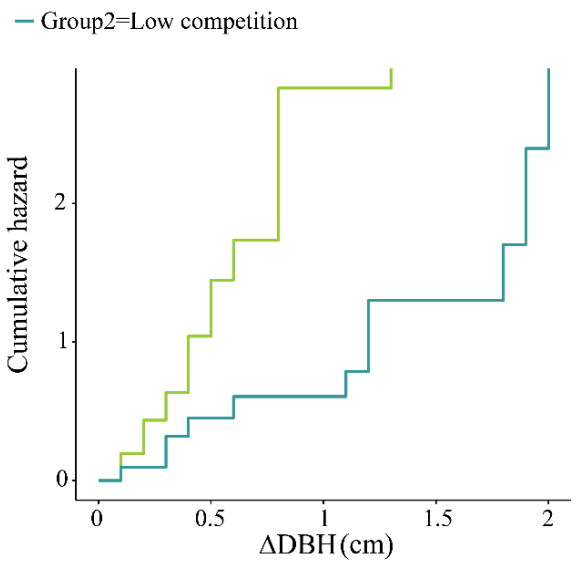

(b)

Figure 6. The survival and hazard curves between different competition groups. (a) The survival probability of different competition groups; (b) the cumulative hazard of different competition groups. 
Table 4. The effect of competition status on tree mortality based on the Cox proportional-hazards analysis.

\begin{tabular}{cccccc}
\hline Variable & Cofficient & Hazard Ratio & $\begin{array}{c}\text { Wald Test } \\
(\boldsymbol{p} \text {-Value })\end{array}$ & $\begin{array}{c}\text { Likehood Radio Test } \\
(\boldsymbol{p} \text {-Value })\end{array}$ & $\begin{array}{c}\text { Logrank Test } \\
(\boldsymbol{p} \text {-Value })\end{array}$ \\
\hline TOI & -1.0703 & 0.3429 & $\begin{array}{c}5.62 \\
(0.02 *)\end{array}$ & $\begin{array}{c}6.11 \\
(0.01 *)\end{array}$ & $\begin{array}{c}6.04 \\
(0.01 *)\end{array}$ \\
\hline
\end{tabular}

The coefficient is estimated by Cox regression. A positive coefficient indicates that the high-competition group suffered a higher hazard risk than the low-competition group, while a negative coefficient indicates that the low-competition group suffered a higher hazard risk than the high-competition group; hazard ratio is the ratio of the low-competition group versus the high-competition group; ${ }^{*}$ indicates $p<0.05$.

\section{Discussion}

As stated above, the competition among trees can be characterized as aboveground and belowground. The aboveground competition primarily focuses on the competition for light and growing space $[10,23,24]$. Thus, concerning the horizontal dimension, many CIs have been developed to focus on the crown's effective projection area [53] to evaluate the actual light and space competition. However, the light and space competition among trees in the vertical dimension is more complicated and assumed to be size-asymmetric [10]. As such, the vertical dimension has not been legitimately evaluated with previous CIs [10]. For example, a shorter tree undergoes disproportionate pressure from light competition due to the shading effect of taller trees [34]. In this scenario, the taller and shorter trees were exposed to the same magnitude of competitive pressure from each other, which is recognized as symmetrical. However, this competition pressure may require higher resistance from the shorter trees, which is manifested in longitudinal growth, and, subsequently, an asymmetric effect is produced. Thus, incorporating only the size ratio (e.g., DBH ratio according to Bella [23] and volume ratio according to Ek and Monserud [24]), expressing the symmetric competition in a CI may not express the trees' actual vertical competition status.

As demonstrated in individual tree simulation, the $\mathrm{AO}_{\mathrm{M}}$ index, which incorporated the tree height size ratio, did not reflect the competition status changes when the crown position and crown length changed in the vertical dimension. This is because the function and structure of the crown and bole remain highly divergent. In the horizontal dimension, tree competition could be represented by crown diameter ratio or bole diameter ratio (always represented as diameter at breast height) due their strong correlation relationship. However, in the vertical dimension, trees shared different bole lengths and crown lengths, even though they showed similar tree heights (e.g., neighbor trees in conditions 1 and 2 of Figure 7). Considering the competition mode difference in the horizontal and vertical dimensions, the light and space competition of trees in the vertical direction may not be simply represented by using tree-size-based parameters, but rather by adding crown-relationship-based parameters. For example, with the conditions shown in Figure 7, the subject trees in conditions 1 and 2 suffered different competition pressures in the vertical dimension. This difference could be accurately explained by the TOI (including the crown-relationship-based parameter). However, the CIs that used only the tree-size-based parameter showed no difference between these conditions. Thus, we modified the $\mathrm{AO}$ index by incorporating two modification coefficients that reduce the excessive effect of smaller neighbor trees [10] to improve its vertical-dimensional competition evaluation ability. In addition, considering the differences between light and growing space competition, two modification coefficients were based on different calculation methods of the crown relationship. The individual-tree simulation results showed that adding modification coefficients significantly contributed to the TOI's vertical-dimensional competition evaluation ability compared to $\mathrm{AO}_{\mathrm{M}}$, and enabled it to express the subject tree's competition status changes when the relationship among the crowns changed in the vertical dimension. 


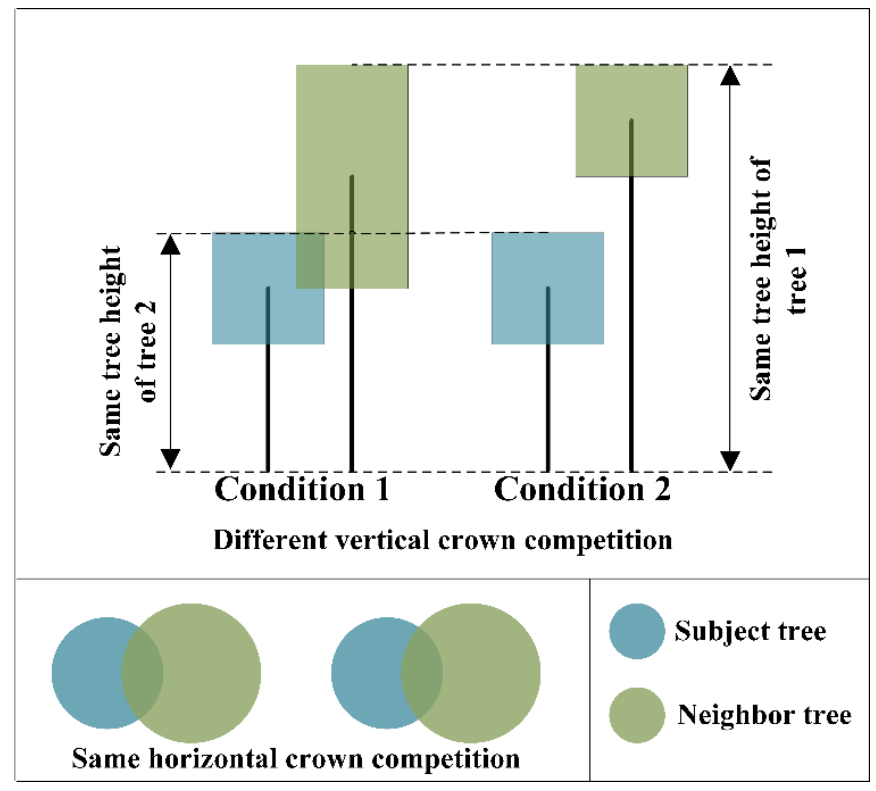

Figure 7. The limitation of tree-size-parameter-based CIs in vertical competition evaluation.

The BAI models that incorporate individual trees' competition status can be more accurate than models that concentrate only on tree size [54]. Therefore, researchers always evaluated CIs by using a BAI model that incorporates CIs $[16,55,56]$. In this work, the BAI model that incorporated the $\mathrm{AO}_{\mathrm{M}}$ index showed better performance than the benchmark BAI model. This result is in good agreement with Pretzsch [10], who promoted the idea that the AO-based index always outperforms most other CIs and can perform satisfactorily in most forest types. In addition, the BAI model that incorporated the TOI showed the best model fitting performance and model validation performance. This indicates that the TOI, as a modification of the $\mathrm{AO}$ index, was more efficient in quantifying individual trees' actual competition status in mixed forests. This is because adding the TOI, with its crown-relationship-based parameters, can effectively improve the accuracy of the AO index.

The competition also influenced tree mortality in both natural and planted forests [57]. Researchers hold different standpoints for the effect of competition on tree mortality and estimated mortality by different methods $[58,59]$. In forestry, competition is widely used as the representation of the social positions of trees in mortality models [10]—for example, basal area in lager trees (BAL) in Pukkala's model [60], or crown closure in higher trees (CCH) in Hann and Wang's model [61]. These models could represent the contributions of different variables to tree death, and qualitatively described the effects of different levels of specific variables on tree mortality. For example, Pretzsch [10] reported that trees in lower social positions might have a higher mortality rate than trees in higher social positions, which agreed with our Kaplan-Meier analysis result in mixed forests. On the one hand, trees in the low-competition group live in environments with relatively adequate resources, and have a low probability of dying [62]. On the other hand, trees in the high-competition group showed a lower growth rate and a bigger tree height-diameter ratio, reperesenting a high risk of being attacked by insects or disease and wind, respectively [10]. In addition, even though these traditional tree mortality models could describe the relationship between different levels of specific variables and tree death, the quantitative relationship between different levels of competition groups and tree mortality is still unknown. In this study, we used Cox proportional-hazards analysis based on the value of the TOI to explore the effect of different levels of competition on tree mortality. This method helped in quantifying the effect of a specific variable's different level on tree mortality. As our results showed in mixed forests, trees in the low-competition group only suffered $34.29 \%$ of hazard risk of that which trees in the high-competition group suffered. This result indicated that keeping the competition pressure 
of trees in the lower level (TOI value less than 1) could effectively reduce the death rate of trees in mixed forests.

Overall, due to the incorporation of crown-relationship-based parameters, the TOI showed some improvements over the $\mathrm{AO}_{\mathrm{M}}$ index in actual competition evaluation capability in mixed forests, and could be effectively used in survival analysis. However, the total numbers of research plots and forest types in our study are limited. Ideally, more forest types and research plots should be included in future three-dimensional competition research.

\section{Conclusions}

Competition index research is crucial for understanding actual tree competition status and could provide new evidence in sustainable forest management. In this work, we proposed and verified the TOI, a new CI based on the modification of AO, and applied it in Kaplan-Meier survival and Cox proportional-hazards analyses. The results showed that: (1) compared to the $\mathrm{AO}_{\mathrm{M}}$, the TOI has improved the quantization ability in the vertical direction; (2) in mixed forests, the TOI showed a better evaluation capability than the $\mathrm{AO}_{\mathrm{M}}, \mathrm{SCI}$, and Hegyi index in the fitting goodness test and cross-validation of growth models; (3) the low-competition group (consisting of trees with TOI values of lower than 1) only suffered $34.29 \%$ of the hazard risk that the high-competition group (consisting of trees with TOI values higher than 1) suffered in mixed forests. These results substantiate that the TOI showed excellent performance in actual competition evaluation mixed forests and, thus, could offer a more accurate understanding of tree competition, which helps sustainable forest management planners make more informed decisions.

Author Contributions: Conceptualization, B.W., Y.B., W.L., and P.Z.; Data curation, B.W., Y.B., G.T., and C.Y.; Formal analysis, B.W., Y.B., and G.T.; Funding acquisition, W.L. and P.Z.; Investigation, B.W. and Y.Y.; Methodology, B.W., Y.B., C.Y., X.Z., and Y.Y.; Project administration, W.L. and P.Z.; Resources, W.L. and P.Z.; Software, B.W., Y.B., G.T., and C.Y.; Supervision, X.Z., W.L., and P.Z.; Validation, B.W., Y.B., G.T., and C.Y.; Visualization, B.W. and Y.B.; Writing—original draft, B.W.; Writing-review and editing, Y.B., G.T., C.Y., X.Z., W.L., P.Z., Y.Y., and R.G. All authors have read and agreed to the published version of the manuscript.

Funding: This work was supported by the National Key Research and Development Program of China, gran number: 2016YFD060020305 and the Shaanxi Forest Department, grant number: SHLY-2018-02.

Acknowledgments: This work was supported by the National Key Research and Development Program of China, grant number: 2016YFD060020305, and the Shaanxi Forest Department, grant number: SHLY-2018-02. We wish to acknowledge Yuanbo Zhou for offering advice about our work and the Xiaolong Mountain Forest Service for their help in forest surveys.

Conflicts of Interest: The funders had no role in the design of the study; in the collection, analyses, or interpretation of data; in the writing of the manuscript, or in the decision to publish the results.

\section{References}

1. Peng, C. Understanding the role of forest simulation models in sustainable forest management. Environ. Impact Assess. Rev. 2000, 20, 481-501. [CrossRef]

2. Ford, E.D.; Sorrensen, K.A. Theory and models of inter-plant competition as a spatial process. In Individual-Based Models and Approaches in Ecology: Populations, Communities, and Ecosystems; Taylor \& Francis: Abingdon, UK, 1992; pp. 363-407.

3. Zhang, J.; Huang, S.; He, F. Half-century evidence from western Canada shows forest dynamics are primarily driven by competition followed by climate. Proc. Natl. Acad. Sci. USA 2015, 112, 4009-4014. [CrossRef] [PubMed]

4. Fujimori, T. Ecological and Silvicultural Strategies for Sustainable Forest Management; Elsevier: Amsterdam, The Netherlands, 2001.

5. Weiskittel, A.R.; Hann, D.W.; Kershaw, J.A., Jr.; Vanclay, J.K. Forest Growth and Yield Modeling; John Wiley \& Sons: Hoboken, NJ, USA, 2011.

6. Vanclay, J.K.; Skovsgaard, J.P. Evaluating forest growth models. Ecol. Model. 1997, 98, 1-12. [CrossRef]

7. Aarssen, L.W. Interpretation of the evolutionary consequences of competition in plants: An experimental approach. Oikos 1985, 45, 99-109. [CrossRef] 
8. Brooker, R.W.; Kikvidze, Z. Importance: An overlooked concept in plant interaction research. J. Ecol. 2008, 96, 703-708. [CrossRef]

9. Hegyi, F. A simulation model for managing jack-pine standssimulation. RoyalColl. For. Res. Notes 1974, 30, 74-90.

10. Pretzsch, H. Forest Dynamics, Growth, and Yield; Springer: Berlin/Heidelberg, Germany, 2009; pp. 1-39.

11. Hui, G.; Wang, Y.; Zhang, G.; Zhao, Z.; Bai, C.; Liu, W. A novel approach for assessing the neighborhood competition in two different aged forests. For. Ecol. Manag. 2018, 422, 49-58. [CrossRef]

12. Tomé, M.; Burkhart, H.E. Distance-dependent competition measures for predicting growth of individual trees. For. Sci. 1989, 35, 816-831.

13. Lee, W.-K.; Von Gadow, K. Iterative bestimmung der konkurrenzbäume in Pinus densiflora Beständen. Allg. Forst-und Jagdztg. 1997, 168, 41-45.

14. Glover, G.R.; Hool, J.N. A basal area ratio predictor of loblolly pine plantation mortality. For. Sci. 1979, 25, 275-282.

15. Biging, G.S.; Dobbertin, M. A comparison of distance-dependent competition measures for height and basal area growth of individual conifer trees. For. Sci. 1992, 38, 695-720.

16. Pukkala, T.; Kolström, T. Competition indices and the prediction of radial growth in Scots pine. Silva Fenn. 1987, 21, 55-67. [CrossRef]

17. Hann, D.W.; Ritchie, M.W. Height growth rate of Douglas-fir: A comparison of model forms. For. Sci. 1988, 34, 165-175.

18. Krajicek, J.E.; Brinkman, K.A.; Gingrich, S.F. Crown competition-A measure of density. For. Sci. 1961, 7, 35-42.

19. Soares, P.; Tomé, M. GLOBTREE: An individual tree growth model for Eucalyptus globulus in Portugal. In Modelling Forest Systems; CAB International: Wallingford, CT, USA, 2003; pp. 97-110.

20. Munro, D.D. Forest growth models-a prognosis. In Growth Models for Tree and Stand Simulation; Department of Forest Yield Research, Royal College of Forestry: Stockholm, Sweden, 1974; Volume 30, pp. 7-21.

21. Arney, J.D. Tables for Quantifying Competitive Stress on Individual Trees. Inf. Rep. BC-X-78. Canadian Forestry Service, Pacific Forest Research Center: Victoria, BC, Canada, 1973. Available online: https: //cfs.nrcan.gc.ca/pubwarehouse/pdfs/26500.pdf (accessed on 1 March 2020).

22. Daniels, R.F. Simple competition indices and their correlation with annual loblolly pine tree growth. For. Sci. 1976, 22, 454-456.

23. Bella, I. A new competition model for individual trees. For. Sci. 1971, 17, 364-372.

24. Ek, A.; Monserud, R. Forest: A Computer Model for Simulating the Growth and Reproduction of Mixed Species Forest Stands; University of Wisconsin: Madison, WI, USA, 1974. [CrossRef]

25. Contreras, M.A.; Affleck, D.; Chung, W. Evaluating tree competition indices as predictors of basal area increment in western Montana forests. For. Ecol. Manag. 2011, 262, 1939-1949. [CrossRef]

26. Danalatos, N.G.; Archontoulis, S.V.; Mitsios, I. Potential growth and biomass productivity of Miscanthus $\times$ giganteus as affected by plant density and N-fertilization in central Greece. Biomass Bioenergy 2007, 31, 145-152. [CrossRef]

27. Kucharik, C.J.; Norman, J.M.; Gower, S.T. Characterization of radiation regimes in nonrandom forest canopies: Theory, measurements, and a simplified modeling approach. Tree Physiol. 1999, 19, 695-706. [CrossRef]

28. Van Pelt, R.; North, M.P. Analyzing canopy structure in Pacific Northwest old-growth forests with a stand-scale crown model. Northwest Sci. 1996, 70, 15-30.

29. Hatch, C.R.; Gerrard, D.J.; Tappeiner, J.C., II. Exposed crown surface area: A mathematical index of individual tree growth potential. Can. J. For. Res. 1975, 5, 224-228. [CrossRef]

30. Opie, J.E. Predictability of individual tree growth using various definitions of competing basal area. For. Sci. 1968, 14, 314-323.

31. Daniels, R.F.; Burkhart, H.E.; Clason, T.R. A comparison of competition measures for predicting growth of loblolly pine trees. Can. J. For. Res. 1986, 16, 1230-1237. [CrossRef]

32. Tennent, R. Competition quotient in young Pinus radiate. N. Z. J. For. Sci. 1975, 5, 230-234.

33. Martin, G.L.; Ek, A.R. A comparison of competition measures and growth models for predicting plantation red pine diameter and height growth. For. Sci. 1984, 30, 731-743.

34. Freckleton, R.; Watkinson, A. Asymmetric competition between plant species. Funct. Ecol. 2001, 15, 615-623. [CrossRef] 
35. Schwinning, S.; Weiner, J. Mechanisms determining the degree of size asymmetry in competition among plants. Oecologia 1998, 113, 447-455. [CrossRef] [PubMed]

36. Kitikidou, K.; Apostolopoulou, E. Applying survival analysis for assessment of forests sustainable development. Renew. Sustain. Energy Rev. 2011, 15, 851-855. [CrossRef]

37. Waters, W.E. The life table approach to analysis of insect impact. J. For. 1969, 67, 300-304.

38. Zens, M.S.; Peart, D.R. Dealing with death data: Individual hazards, mortality and bias. Trends Ecol. Evol. 2003, 18, 366-373. [CrossRef]

39. Bigler, C.; Bugmann, H. Assessing the performance of theoretical and empirical tree mortality models using tree-ring series of Norway spruce. Ecol. Model. 2004, 174, 225-239. [CrossRef]

40. Bigler, C.; Bugmann, H. Predicting the time of tree death using dendrochronological data. Ecol. Appl. 2004, 14, 902-914. [CrossRef]

41. Canham, C.D.; LePage, P.T.; Coates, K.D. A neighborhood analysis of canopy tree competition: Effects of shading versus crowding. Can. J. For. Res. 2004, 34, 778-787. [CrossRef]

42. Husch, B.; Beers, T.W.; Kershaw, J.A., Jr. Forest Mensuration; John Wiley \& Sons: Hoboken, NJ, USA, 2002.

43. Canham, C.D.; Papaik, M.J.; Uriarte, M.; McWilliams, W.H.; Jenkins, J.C.; Twery, M.J. Neighborhood analyses of canopy tree competition along environmental gradients in new england forests. Ecol. Appl. 2006, 16, 540-554. [CrossRef]

44. Groot, A. A model to estimate light interception by tree crowns, applied to black spruce. Can. J. For. Res. 2004, 34, 788-799. [CrossRef]

45. Stadt, K.J.; Lieffers, V.J. MIXLIGHT: A flexible light transmission model for mixed-species forest stands. Agric. For. Meteorol. 2000, 102, 235-252. [CrossRef]

46. Hanus, M.L. Modeling Light Competition in the Forests of Western Oregon. Ph.D. Thesis, Oregon State University, Corvallis, OR, USA, 2003.

47. Hans, P. Forest Dynamics, Growth and Yield: From Measurement to Model; Springer: Berlin/Heidelberg, Germany, 2009.

48. Wykoff, W.R. A basal area increment model for individual conifers in the northern Rocky Mountains. For. Sci. 1990, 36, 1077-1104.

49. Kiernan, D.H.; Bevilacqua, E.; Nyland, R.D. Individual-tree diameter growth model for sugar maple trees in uneven-aged northern hardwood stands under selection system. For. Ecol. Manag. 2008, 256, 1579-1586. [CrossRef]

50. Efron, B. Estimating the error rate of a prediction rule: Improvement on cross-validation. J. Am. Stat. Assoc. 1983, 78, 316-331. [CrossRef]

51. Yang, Y.; Huang, S. Suitability of five cross validation methods for performance evaluation of nonlinear mixed-effects forest models-A case study. Forestry 2014, 87, 654-662. [CrossRef]

52. Cox, D.R.; Oakes, D. Analysis of Survival Data; CRC Press: Boca Raton, FL, USA, 1984; Volume 21.

53. Rivas, J.C.; González, J.Á.; Aguirre, O.; Hernandez, F. The effect of competition on individual tree basal area growth in mature stands of Pinus cooperi Blanco in Durango (Mexico). Eur. J. For. Res. 2005, 124, 133-142. [CrossRef]

54. Anning, A.K.; McCarthy, B.C. Competition, size and age affect tree growth response to fuel reduction treatments in mixed-oak forests of Ohio. For. Ecol. Manag. 2013, 307, 74-83. [CrossRef]

55. Kahriman, A.; Şahin, A.; Sönmez, T.; Yavuz, M. A novel approach to selecting a competition index: The effect of competition on individual-tree diameter growth of Calabrian pine. Can. J. For. Res. 2018, 48, 1217-1226. [CrossRef]

56. McTague, J.; Weiskittel, A. Individual-tree competition indices and improved compatibility with stand-level estimates of stem density and long-term production. Forests 2016, 7, 238. [CrossRef]

57. Fernández-Manjarrés, J.F.; Ruiz-Benito, P.; Zavala, M.A.; Camarero, J.J.; Pulido, F.; Proença, V.; Navarro, L.; Sansilvestri, R.; Granda, E.; Marqués, L. Forest adaptation to climate change along steep ecological gradients: The case of the Mediterranean-temperate transition in South-Western Europe. Sustainability 2018, 10, 3065. [CrossRef]

58. Linares, J.C.; Camarero, J.J.; Carreira, J.A. Competition modulates the adaptation capacity of forests to climatic stress: Insights from recent growth decline and death in relict stands of the Mediterranean fir Abies pinsapo. J. Ecol. 2010, 98, 592-603. [CrossRef] 
59. de Toledo, J.J.; Magnusson, W.E.; Castilho, C.V. Competition, exogenous disturbances and senescence shape tree size distribution in tropical forest: Evidence from tree mode of death in C entral A mazonia. J. Veg. Sci. 2013, 24, 651-663. [CrossRef]

60. Pukkala, T.; Lähde, E.; Laiho, O. Growth and yield models for uneven-sized forest stands in Finland. For. Ecol. Manag. 2009, 258, 207-216. [CrossRef]

61. Hann, D.W.; Wang, C.-H. Mortality Equations for Individual Trees in the Mixed-Conifer Zone of Southwest Oregon; Oregon State University: Corvallis, OR, USA, 1990.

62. Yang, Y.; Titus, S.J. Maximum size-density relationship for constraining individual tree mortality functions. For. Ecol. Manag. 2002, 168, 259-273. [CrossRef]

(C) 2020 by the authors. Licensee MDPI, Basel, Switzerland. This article is an open access article distributed under the terms and conditions of the Creative Commons Attribution (CC BY) license (http://creativecommons.org/licenses/by/4.0/). 